\title{
Aspectos econômicos do uso de fontes orgânicas de nutrientes associadas a sistemas de preparo do solo
}

\author{
Economical aspects of organic nutrient sources associated with soil tillage systems
}

\author{
Carla Maria Pandolfo ${ }^{\mathrm{I}}$ Carlos Alberto Ceretta ${ }^{\mathrm{II}}$
}

\section{RESUMO}

A análise econômica é fundamental para a tomada de decisão no uso de fontes orgânicas de nutrientes. $O$ objetivo do trabalho foi avaliar aspectos econômicos do uso de fontes orgânicas de nutrientes para auxiliar a tomada de decisão sobre o seu uso em diferentes condições de manejo do solo. Foi utilizado um experimento conduzido durante nove anos na Estação Experimental da Epagri de Campos Novos/ SC. Os tratamentos consistiram da combinação de cinco sistemas de preparo (plantio direto, preparo reduzido, preparo convencional, preparo convencional com resíduos queimados e preparo convencional com resíduos retirados), combinados com quatro fontes de nutrientes (TES - testemunha, sem aplicação de nutrientes, AM - adubação mineral de acordo com a recomendação para cada cultura, EA - $5 \mathrm{mg} \mathrm{ha}^{-1}$ de matéria úmida de cama de aves, ELB - $60 \mathrm{~m}^{3} \mathrm{ha}^{-1}$ de dejeto líquido de bovinos e; ELS - 40m $\mathrm{ha}^{-1}$ de dejeto líquido de suínos). Os atributos econômicos utilizados foram os custos variáveis (CV), a receita bruta $(R B)$ e o custo da correção da fertilidade com calcário, $P$ e $K$ (CC), após nove anos de aplicação das fontes de nutrientes. A interpretação para cada combinação de fonte de nutriente e sistema de preparo do solo foi feita por meio de figuras triangulares e a área das mesmas com intervalo de confiança a $90 \%$ de probabilidade. Concluiuse que o desempenho econômico das fontes orgânicas de nutrientes foi dependente do sistema de preparo do solo, sendo que as fontes apresentaram melhor desempenho no sistema plantio direto. $O$ esterco de aves e o esterco líquido de suínos foram as fontes que apresentaram melhor desempenho econômico. O esterco líquido de suínos e o esterco líquido de bovinos, mesmo apresentando áreas diferentes, foram as fontes que apresentaram menor variabilidade nos atributos econômicos avaliados, não havendo um atributo que se destaque dos demais. O custo da correção da fertilidade do solo com calcário, $P$ e K, após nove anos de aplicação das fontes de nutrientes, tem importante participação no desempenho econômico das mesmas.
Palavras-chaves: dejetos, resíduos orgânicos, manejo do solo, modelo de análise econômica.

\section{ABSTRACT}

Economical analysis is important to make decision on the use of organic nutrient sources. The objective of this study was to elaborate an economical analysis of different nutrient sources to help farmers and technicians to make decision about the use of these sources at different soil management. The study was carried out at the Epagri Experimental Station of Campos Novos, using a long-term experiment. The treatments were a combination of five tillage systems (no-till; chisel plow; conventional tillage; conventional tillage with crop residues burned and conventional tillage with crop residues removed from the field), with four nutrient sources (TES=control, no fertilizer; AM=mineral fertilizer according with technical recommendation for each crop; $E A=5 \mathrm{mg} \mathrm{ha}^{-1}$ of moisture poultry litter; $E L B=60 \mathrm{~m}^{3} \mathrm{ha}^{-1}$ of liquid cattle manure; and $E L S=40 \mathrm{~m}^{3} \mathrm{ha}^{-1}$ of slurry pig manure). The economical attributes used were variable costs of production, total income, and the cost of the necessity of lime and fertilizers application to improve soil chemical condition after nine years of applying treatments. A model was used to quantify and analyse the effect of nutrient sources in economical aspects, for each nutrient source within each soil tillage. The outputs were triangular pictures and their areas with $90 \%$ confidence limits. It was concluded that economical aspect effects of the organic nutrient sources were dependent on tillage systems, and the better performance was in no-till system. EA and ELS showed better economical results. ELS and ELB, even showing different picture areas, were the sources that showed lesser variability in economical attribute evaluated, and did not have one highlight attribute among them. The use of cost of the necessity of lime and fertilizers application to improve soil chemical condition after nine years of applying treatments, showed important participation in nutrient source evaluation in respect to economical aspect.

Key words: manure, organic residues, soil management, economical analysis model.

\footnotetext{
'Empresa de Pesquisa Agropecuária e Extensão Rural de Santa Catarina (EPAGRI), CP 116, 89620-000, Campos Novos, SC, Brasil. E-mail: pandolfo@epagri.sc.gov.br. Autor para correspondência.

"Departamento de Solos, Centro de Ciências Rurais (CCR), Universidade Federal de Santa Maria (UFSM), Santa Maria, RS, Brasil.
} 


\section{INTRODUÇÃO}

Além da perspectiva da produtividade das culturas, o agricultor precisaa considerar aspectos econômicos para tomada de decisão, especialmente no que se refere ao planejamento da escolha dos insumos a serem utilizados. Referindo-se à agricultura orgânica, ALTMANN \& OLTRAMARI (2004) ressaltam que provavelmente a dimensão econômica seja o principal aspecto considerado na decisão dos produtores para continuar na atividade, fazer novos investimentos ou mesmo abandonar o setor. A diminuição dos custos de produção, por meio do uso de dejetos disponíveis na propriedade ou na comunidade, pode ser uma das formas de maximizar o lucro do produtor e tornar a atividade viável economicamente.

A eficiência econômica dos dejetos depende do seu tipo e de sua composição, das doses, do sistema de preparo do solo, do tipo de solo e de cultura e da distância entre a esterqueira e a lavoura, entre outros aspectos (SCHERER \& BARTZ, 1984; SCHMITT, 1995; SCHERER, 1998; ARAJI, 2001; SCHERER, 2005). A análise econômica simplificada do uso dos dejetos pode ser feita por meio do conjunto de alguns atributos, tais como custo de aquisição e distribuição do esterco e variação da produção física da cultura estudada. Em uma análise econômica mais abrangente, poderiam ser incluídos também atributos que mostrassem as alterações no solo utilizado para a produção agrícola (degradação ou melhoria), em função das práticas aplicadas ao longo do tempo. Esta análise mais abrangente pode ser realizada por meio de uma avaliação conjunta dos atributos estudados, cujos detalhes encontram-se em PANDOLFO (2005).

O objetivo deste trabalho foi efetuar uma avaliação econômica de fontes de nutrientes, associadas a sistemas de preparo do solo, visando oferecer subsídios para a tomada de decisão sobre o uso de dejetos como fontes de nutrientes às culturas.

\section{MATERIAL E MÉTODOS}

O experimento foi conduzido de 1994 a 2003, na Estação Experimental da EPAGRI em Campos Novos, no Planalto Sul Catarinense, em um Nitossolo Vermelho, onde foram avaliados os atributos econômicos receita bruta (RB), custos variáveis (CV) e custo da correção da fertilidade do solo com calcário, fósforo e potássio (CC), após nove anos de aplicação das fontes de nutrientes. O delineamento foi em blocos subdivididos, com os sistemas de preparo do solo feitos em faixas transversais ao declive do terreno e as fontes de nutrientes em faixas transversais aos sistemas de preparo, ambas com $6 \mathrm{~m}$ de largura e $30 \mathrm{~m}$ de comprimento. Os sistemas de preparo do solo foram: plantio direto (PD), preparo reduzido com uma escarificação mais uma gradagem (PRE), preparo convencional com uma lavração mais duas gradagens (PCO), preparo convencional com palha queimada (PCQ) e preparo convencional com palha retirada (PCR). Anualmente foram aplicadas quatro fontes de nutrientes: $5 \mathrm{t} \mathrm{ha}^{-1} \mathrm{ano}^{-1}$ de cama de aviário (EA), base úmida, $40 \mathrm{~m}^{3} \mathrm{ha}^{-1}$ ano ${ }^{-1}$ de dejeto líquido de suínos (ELS), $60 \mathrm{~m}^{3} \mathrm{ha}^{-1}$ ano $^{-1}$ de dejeto líquido de bovinos confinados (ELB), adubação mineral de reposição (AM) e, uma testemunha sem aplicação de nutrientes (TES). As fontes orgânicas e a mineral foram aplicadas antes da última gradagem, quando era o caso, ou sobre a superfície do solo no PD. Na adubação mineral, foi utilizada a recomendação de adubação de reposição (CQFS RS/SC, 2004), usando-se uréia, superfosfato triplo e cloreto de potássio. As fontes orgânicas foram adquiridas na região e o total aplicado com cama de aves nos nove anos foi de 1.106, 847 e $882 \mathrm{~kg} \mathrm{ha}^{-1}$ de N, $\mathrm{P}_{2} \mathrm{O}_{5}$ e $\mathrm{K}_{2} \mathrm{O}$, respectivamente, com dejeto líquido de bovinos de 732, 531 e $1.019 \mathrm{~kg} \mathrm{ha}^{-1}$ de $\mathrm{N}, \mathrm{P}_{2} \mathrm{O}_{5}$ e $\mathrm{K}_{2} \mathrm{O}$, respectivamente, com dejeto líquido de suínos de 1.000 , 1.507 e $526 \mathrm{~kg} \mathrm{ha}^{-1}$ de $\mathrm{N}, \mathrm{P}_{2} \mathrm{O}_{5}$ e $\mathrm{K}_{2} \mathrm{O}$, respectivamente, e, com adubo mineral, de 675, 450 e $690 \mathrm{~kg} \mathrm{ha}^{-1}$ de N, $\mathrm{P}_{2} \mathrm{O}_{5}$ e $\mathrm{K}_{2} \mathrm{O}$, respectivamente.

Implantou-se uma rotação de culturas com ciclos de três anos, tendo no primeiro ciclo triticale/ soja/ervilhaca comum/milho/aveia preta/feijão e no segundo ciclo o triticale foi substituído por centeio. A produtividade de grãos de milho foi determinada em $16,8 \mathrm{~m}^{2}$ de área útil e para soja e feijão em $4,5 \mathrm{~m}^{2}$. A matéria seca das plantas de cobertura foi determinada antes do seu manejo em $0,25 \mathrm{~m}^{2}$. A produtividade média de soja, milho e feijão e de matéria seca de ervilhaca comum, triticale e centeio estão na tabela 1. A necessidade de calcário, após os nove anos, foi estimada pelo Índice SMP e utilizado calcário dolomítico, enquanto que a necessidade de fósforo e potássio foi baseada na recomendação (CQFS-RS/SC, 2004), a partir dos teores de $\mathrm{P}$ e $\mathrm{K}$ extraídos por Mehlich-1 (TEDESCO et al., 1995) e utilizados superfosfato triplo e cloreto de potássio. A amostragem do solo foi realizada na camada de $0-10 \mathrm{~cm}$ no PD e $0-20 \mathrm{~cm}$ nos demais sistemas.

Os aspectos econômicos do uso das fontes envolveram a análise com geração de triângulos e cálculo das suas áreas e dos intervalos de confiança dessas áreas. A média e o intervalo de confiança também foram determinados para os três atributos usados à figura, os quais se constituíram nos seus eixos, fazendose uso de atributos transformados por meio de 
Tabela 1 - Produtividades médias de grãos de soja, milho e feijão e de matéria seca de ervilhaca comum, aveia preta, triticale e centeio em sistemas de preparo do solo e fontes de nutrientes ao longo dos nove anos do experimento.

\begin{tabular}{|c|c|c|c|c|c|c|c|c|}
\hline Sistemas de preparo do solo & $\begin{array}{l}\text { Fontes de } \\
\text { nutrientes }\end{array}$ & Soja $^{2}$ & Milho $^{2}$ & Feijão $^{2}$ & $\begin{array}{l}\text { Ervilhaca } \\
\text { comum }^{2}\end{array}$ & $\begin{array}{l}\text { Aveia } \\
\text { preta }^{2}\end{array}$ & Triticale $^{3}$ & Centeio $^{4}$ \\
\hline \multirow{5}{*}{ Plantio direto } & TES & 1.547 & 3.335 & 741 & 2.077 & 3.404 & 1.778 & 3.457 \\
\hline & EA & 2.112 & 6.905 & 1.899 & 3.200 & 5.371 & 2.350 & 5.414 \\
\hline & ELB & 2.075 & 5.113 & 1.418 & 3.171 & 4.508 & 2.008 & 3.604 \\
\hline & ELS & 2.208 & 6.444 & 2.030 & 3.491 & 4.886 & 2.136 & 5.404 \\
\hline & $\mathrm{AM}$ & 1.593 & 5.535 & 1.515 & 2.842 & 5.078 & 1.551 & 4.344 \\
\hline \multirow{5}{*}{ Preparo reduzido } & TES & 1.643 & 3.588 & 842 & 3.054 & 3.357 & 1.971 & 3.824 \\
\hline & EA & 2.249 & 6.816 & 1.994 & 3.200 & 4.842 & 1.629 & 4.357 \\
\hline & ELB & 2.034 & 5.010 & 1.303 & 2.887 & 3.844 & 2.176 & 3.770 \\
\hline & ELS & 2.198 & 6.458 & 2.099 & 3.398 & 4.699 & 2.504 & 5.327 \\
\hline & $\mathrm{AM}$ & 1.757 & 6.251 & 1.793 & 3.043 & 4.347 & 2.241 & 4.363 \\
\hline \multirow{5}{*}{ Preparo convencional } & TES & 1.829 & 3.247 & 560 & 1.930 & 2.820 & 1.323 & 2.584 \\
\hline & EA & 2.102 & 6.122 & 1.468 & 3.133 & 5.023 & 1.618 & 3.904 \\
\hline & ELB & 2.048 & 4.942 & 1.040 & 2.458 & 3.573 & 1.388 & 4.660 \\
\hline & ELS & 2.200 & 6.309 & 1.800 & 3.273 & 4.666 & 1.670 & 4.504 \\
\hline & $\mathrm{AM}$ & 1.883 & 6.672 & 1.670 & 2.690 & 4.553 & 1.832 & 4.710 \\
\hline \multirow{5}{*}{$\begin{array}{l}\text { Preparo convencional } \\
\text { palha queimada }\end{array}$} & TES & 1.556 & 3.062 & 674 & 1.648 & 4.049 & 1.688 & 2.470 \\
\hline & EA & 2.280 & 5.972 & 1.861 & 3.119 & 4.950 & 2.223 & 4.264 \\
\hline & ELB & 1.845 & 4.099 & 1.196 & 2.808 & 5.094 & 2.071 & 3.277 \\
\hline & ELS & 2.429 & 5.499 & 1.940 & 3.275 & 4.581 & 1.919 & 4.274 \\
\hline & $\mathrm{AM}$ & 2.024 & 6.683 & 1.918 & 2.656 & 4.445 & 1.981 & 4.007 \\
\hline \multirow{5}{*}{$\begin{array}{l}\text { Preparo convencional com } \\
\text { palha retirada }\end{array}$} & TES & 1.476 & 2.554 & 519 & 1.797 & 2.763 & 1.439 & 2.623 \\
\hline & EA & 2.405 & 5.549 & 1.675 & 2.738 & 4.972 & 2.334 & 4.570 \\
\hline & ELB & 1.979 & 3.646 & 1.054 & 1.884 & 3.753 & 2.064 & 4.260 \\
\hline & ELS & 2.191 & 4.988 & 1.688 & 2.460 & 4.412 & 2.096 & 3.817 \\
\hline & $\mathrm{AM}$ & 1.907 & 5.838 & 1.623 & 2.072 & 4.180 & 1.981 & 2.993 \\
\hline
\end{tabular}

${ }^{1}$ EA=Dejeto de aves; ELB=Dejeto líquido de bovinos; ELS= Dejeto líquido de suínos; AM=Adubo mineral.

${ }^{2}$ Três anos; ${ }^{3}$ Um ano; ${ }^{4}$ Dois anos.

relativizações para estes apresentarem valor entre zero e um, sendo que valores igual ou próximos de 1,0 refletem um melhor potencial do uso das fontes e valores igual ou próximos de zero refletem um limitante no seu uso. Os vértices dos triângulos correspondem ao valor de cada atributo, plotados no eixo correspondente. A área do triângulo externo correspondeu à soma das áreas de três triângulos internos, cujos lados correspondem ao comprimento dos dois eixos adjacentes, sendo a área calculada por meio da fórmula $\mathrm{A}=\mathrm{E} 1 \times \mathrm{E} 2 \times(\operatorname{sen} \alpha / 2)$, sendo $\alpha=120^{\circ}$ (Figura 1).
No cálculo dos intervalos de confiança da área de cada triângulo, foi utilizado o programa @Risk 4.5 para Excel. Os dados de entrada do modelo foram a média, o desvio padrão, o valor máximo e o valor mínimo dos atributos receita bruta (RB), custos variáveis (CV) e custo da correção da fertilidade com calcário, P e K (CC), para cada combinação de sistemas de preparo e de fontes. Com isso, o programa calculou a área da figura para 1.000 combinações dos valores dos atributos, tomados três a três, e o intervalo de confiança dessa área e dos atributos relativizados $\left(\mathrm{RB}_{\mathrm{r}}, \mathrm{CV}_{\mathrm{r}} \mathrm{e}\right.$ $\mathrm{CC}_{\mathrm{r}}$ ), a $90 \%$ de probabilidade. As áreas ou os atributos

Ciência Rural, v.38, n.6, set, 2008. 


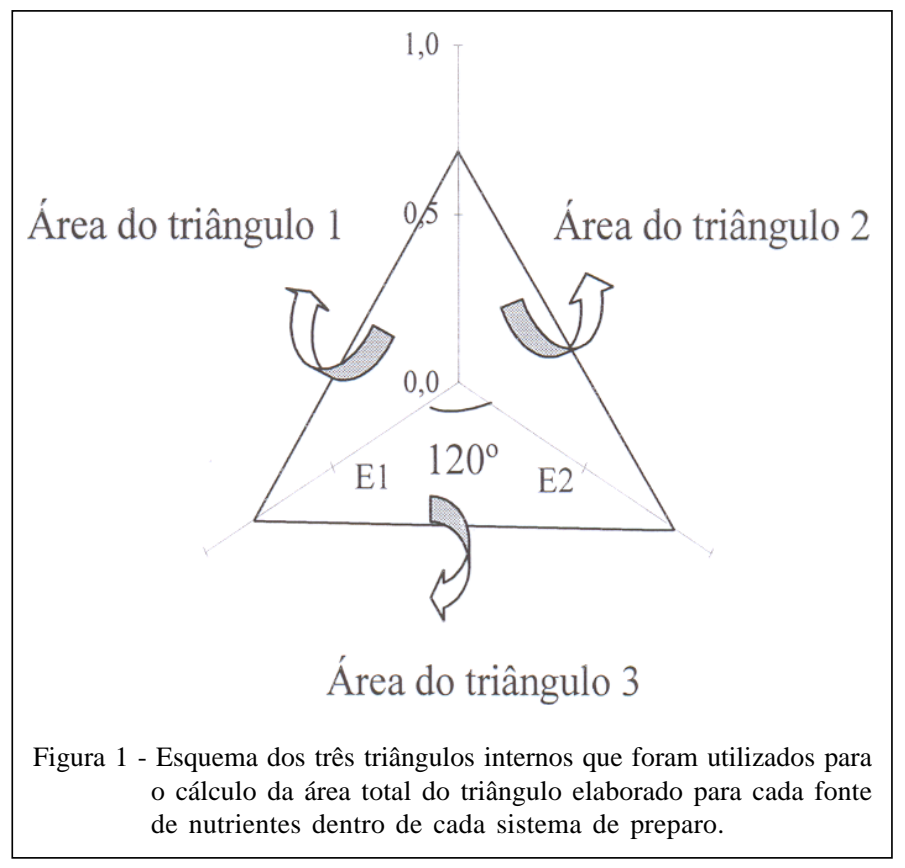

foram estatisticamente diferentes quando os intervalos de confiança, tomados dois a dois, não se sobrepuseram. O modelo permite todas as comparações para combinações de fontes de nutrientes e sistemas de preparo possíveis, mas são adequadas às comparações entre as fontes dentro de cada sistema de preparo e entre os sistemas para uma mesma fonte.

A receita bruta foi obtida multiplicando-se a produção de grãos ou de feno pelo valor unitário (preço histórico do grão ou feno) de cada cultura. No sistema de preparo do solo com palha removida, o material retirado poderia ser utilizado para fenação, e assim teria valor para venda. Nos custos variáveis, foram utilizados parâmetros em outubro de 2003 (ICEPA, 2003) (Tabela 2). Foram utilizados preços históricos de julho de 1994 a junho de 2003 (ICEPA/SC, 2003 e dados da região) com atualização dos preços pelo Índice de Preços ao Consumidor Ampliado (IPCA/IBGE). Quando não estavam disponíveis preços históricos de produtos fitossanitários, os preços foram estimados a partir do valor histórico em dólar de três produtos que tinham relação com os produtos que não se dispunha de preço, considerando o preço em reais em 30/04/2004 (Obtido na COOPERCAMPOS, Campos Novos/SC). O valor em reais considerado para hora máquina ou hora trator foi o de outubro de 2003 (ICEPA/SC, 2003) e os coeficientes técnicos obtidos de várias fontes (Tabela 2). Como o ELB e o ELS não são comercializados, não foram considerados custos de aquisição para estas fontes, sendo considerado apenas o custo para EA, sendo essa a característica na região. Demais custos inerentes à aplicação das fontes orgânicas encontramse na tabela 2. No caso das plantas de cobertura no sistema de preparo PCR, foi considerado o mesmo preço da alfafa para a ervilhaca e para o centeio e a aveia preta. também foi utilizado o preço de venda da alfafa dividido por dois, que corresponde ao preço praticado na região.

A valoração da receita bruta (RB)

foi feita por meioda relativização da RB média anual dos tratamentos em relação ao maior valor obtido no experimento $\left(\mathrm{RB}_{\mathrm{r}}\right)$. A valoração dos custos variáveis $(\mathrm{CV})$ resultou da soma de 1/3 dos custos para cada cultura e o valor final foi relativizado pelo menor custo obtido no experimento $\left(\mathrm{CV}_{\mathrm{r}}\right)$. $\mathrm{O}$ custo de uma adubação mineral com $\mathrm{P}$ e $\mathrm{K}$ e calagem, após nove anos de aplicação dos tratamentos, foi relativizado em relação ao menor valor $\left(\mathrm{CC}_{\mathrm{r}}\right)$. Para diminuir a amplitude de variação deste parâmetro, os dados foram ajustados para valores entre 0,7 e 1,0, por meio da equação $\mathrm{Y}=-0,0009 \mathrm{x}+1$, em que $\mathrm{x}=$ custo $(\mathrm{CC})$ em $\mathrm{R} \$$ ha $^{-1} \mathrm{e} \mathrm{Y}=$ valor corrigido. Este artifício foi utilizado para dar menor peso a este atributo.

\section{RESULTADOS E DISCUSSÃO}

Os três atributos econômicos utilizados na análise permitiram diferenciar economicamente as fontes orgânicas de nutrientes (Figura 2 e Tabela 3). O atributo $\mathrm{CC}_{\mathrm{r}}$ mostrou que a maior valoração deste atributo (menor custo) foi apresentada pelo EA e a menor valoração (maior custo) pelo ELB em quatro sistemas de preparo do solo e pela AM no PCR. Isso pode estar relacionado com a maior concentração de nutrientes no EA, aumentando os teores no solo ao final de nove anos, além da redução da necessidade de calcário neste caso. Em função disto, o EA se diferenciou na maioria das vezes do ELB, ELS e AM, demonstrando que esta fonte se destacou em termos de manter ou melhorar as características químicas do solo. O ELB se diferenciou três vezes do AM, mostrando melhor desempenho no atributo $\mathrm{CC}_{\mathrm{r}}$.

O maior número de comparações diferentes entre as fontes ocorreu no atributo $\mathrm{CV}_{\mathrm{r}}$, com 48 combinações diferentes, constituindo-se em um atributo importante para individualizar as fontes. $\mathrm{Na}$ testemunha foram obtidas as menores $\mathrm{RB}_{\mathrm{r}}$ em todos os sistemas de preparo do solo, devido às baixas produtividades. Por outro lado, devido à similaridade na produtividade de grãos, o EA não se diferenciou do ELS, mas apenas do ELB, em todos os sistemas de 
Tabela 2 - Coeficientes técnicos utilizados no cálculo do custo variável do sistema cultura de inverno/culturas de milho, feijão e soja e no processo de fenação ou silagem das plantas de cobertura.

\begin{tabular}{|c|c|c|c|c|c|c|}
\hline \multirow{2}{*}{ Componentes } & \multirow{2}{*}{ Especificação } & \multirow{2}{*}{$\begin{array}{l}\text { Unidade } \\
\text { referência }\end{array}$} & \multicolumn{3}{|c|}{ Coeficientes } & \multirow{2}{*}{ Fonte } \\
\hline & & & Milho $^{1)}$ & Feijão $^{3)}$ & Soja ${ }^{2)}$ & \\
\hline Semente & Milho híbrido simples & Mil sementes & 60 & - & - & ICEPA/SC (2003) \\
\hline Semente & Feijão e Soja & $\mathrm{kg}$ & - & 50 & 70 & ICEPA/SC (2003) \\
\hline Semente adubo verde $\mathrm{e}^{5)}$ & Ervilhaca, aveia, centeio & $\mathrm{kg}$ & 40 & 100 & 80 & EPAGRI (2003) \\
\hline Plantio cultura+adubo verde ${ }^{6)}$ & trator + plantadeira & hora-trator & 1,8 & 1,8 & 1,8 & ICEPA/SC (2003) \\
\hline Aplicação uréia & trator + distribuidor & hora-trator & 0,5 & 0,5 & - & ICEPA/SC (2003) \\
\hline Aplicação dejeto aves ${ }^{7)}$ & carregar + distribuir & hora-trator & 1 & 1 & 1 & - \\
\hline Aplicação dejeto suínos ${ }^{8)}$ & carregar + distribuir & hora-trator & 2 & 2 & 2 & - \\
\hline Aplicação dejeto bovinos ${ }^{9)}$ & carregar + distribuir & hora-trator & 3 & 3 & 3 & - \\
\hline Aplicação dessecante & trator + pulverizador & hora-trator & 0,5 & - & 0,5 & ICEPA/SC (2003) \\
\hline Aplicação inseticida & trator + pulverizador & hora-trator & 0,5 & 0,5 & 0,5 & ICEPA/SC (2003) \\
\hline Aplicação herbicida & trator + pulverizador & hora-trator & 0,5 & 0,5 & 0,5 & ICEPA/SC (2003) \\
\hline Aração & trator + arado & hora-trator & 3,0 & 3,0 & 3,0 & ICEPA/SC (2003) \\
\hline Aração - Preparo reduzido & trator + arado & hora-trator & 1,5 & 1,5 & 1,5 & ICEPA/SC (2003) \\
\hline Gradagem (1 passada) & trator + grade & hora-trator & 1,0 & 1,0 & 1,0 & ICEPA/SC (2003) \\
\hline Colheita mecânica & automotriz média & $\begin{array}{l}\text { hora } \\
\text { colheitadeira }\end{array}$ & 1,2 & 1,5 & 1,0 & ICEPA/SC (2003) \\
\hline Transporte até armazém & - & - & 0,5 & 0,5 & 0,5 & ICEPA/SC (2003) \\
\hline Silagem ou fenação ${ }^{10)}$ & - & hora trator & 3,5 & 3,5 & 3,5 & - \\
\hline Beneficiamento & - & $\%$ & 2,5 & 2,5 & 2,5 & ICEPA/SC (2003) \\
\hline Seguro agrícola & - & $\%$ & 2,9 & 6,7 & 2,9 & ICEPA/SC (2003) \\
\hline Assistência técnica & - & $\%$ & 2,0 & 2,0 & 2,0 & ICEPA/SC (2003) \\
\hline Outros custos & - & $\%$ & 1,0 & 1,0 & 1,0 & ICEPA/SC (2003) \\
\hline
\end{tabular}

${ }^{1)}$ Baseado no custo de produção do milho, por hectare, conduzido sob alta tecnologia (área média de 40ha, produtividade de grãos de $7.500 \mathrm{~kg}$ $\mathrm{ha}^{-1}$ ) (outubro de 2003) (ICEPA/SC).

${ }^{2)}$ Baseado no custo de produção da soja para área média cultivada de 70 ha e produtividade de grãos de $2.700 \mathrm{~kg}$ ha ${ }^{-1}$ (outubro de 2003 ) (ICEPA/SC).

${ }^{3}$ Baseado no custo de produção do feijão (tração motora) para uma área média de 20ha e produtividade de $1.800 \mathrm{~kg}$ ha ${ }^{-1}$ (ICEPA/SC).

${ }^{4)}$ Saco com 60.000 sementes.

${ }^{5}$ Ervilhaca, centeio e aveia preta, respectivamente.

${ }^{6)}$ Para a semeadura das culturas $1 \mathrm{~h}$ trator cada (ICEPA/SC, outubro de 2003) e 0,8h trator para a semeadura dos adubos verdes de inverno (estimado).

${ }^{7)}$ Valores estimados considerando-se que a distribuição do dejeto é igual à distribuição de calcário (0,5h ha $\left.{ }^{-1}\right)$ mais o mesmo tempo para o carregamento.

${ }^{8)}$ Estimado em 2 horas ha ${ }^{-1}$ para distribuir e carregar em função do volume utilizado.

${ }^{9)}$ Estimado em 3 horas ha ${ }^{-1}$ para distribuir e carregar em função do volume (volume de $50 \%$ a mais do que o dejeto líquido de suínos).

${ }^{10)}$ Estimado 3 horas ha $^{-1}$ para cortar, virar e enfardar e 0,5 hora ha ${ }^{-1}$ para transporte. Fonte: Banco de dados da região de Herval D’Oeste/SC e RASSINI et al. (2003).

preparo do solo. Entretanto, o ELB se diferenciou do ELS em todos os sistemas de preparo, com exceção do PCR. As maiores valorações da $\mathrm{RB}_{\mathrm{r}}$ foram obtidas com o ELS (PD e PCO), EA (PRE, PCR) e AM (PCQ), pois estas três fontes proporcionaram as maiores produtividades de milho e de feijão.

Os triângulos construídos com os três atributos econômicos $\left(\mathrm{RB}_{\mathrm{r}}, \mathrm{CV}_{\mathrm{r}}\right.$ e $\left.\mathrm{CC}_{\mathrm{r}}\right)$ são apresentados na figura 2 para os sistemas de preparo PD e PCR, que tiveram comportamentos distintos. O primeiro aspecto que se pode visualizar na figura é o tamanho dos triângulos, sendo que quanto maior o triângulo melhor é o desempenho econômico da fonte. Observa-se que o EA e o ELS apresentam os maiores triângulos e a TES o menor, em ambos os sistemas de preparo (Figura 2). Nesses triângulos também é possível visualizar se há ou não equilíbrio entre os atributos, pois, quando o comprimento dos eixos for mais próximo de 1,0, maior 0 potencial de uso da fonte em relação àquele atributo (vantagem), enquanto que à medida que se aproxima de zero, maior a limitação de seu uso. Visualmente, observa-se que o atributo que apresentou maior variação entre as fontes de nutrientes foi a $R_{r}$. Por outro lado, no eixo do $\mathrm{CV}_{\mathrm{r}}$ as fontes apresentaram valores na ordem inversa aos outros dois eixos. Como somente a observação visual dos triângulos não 


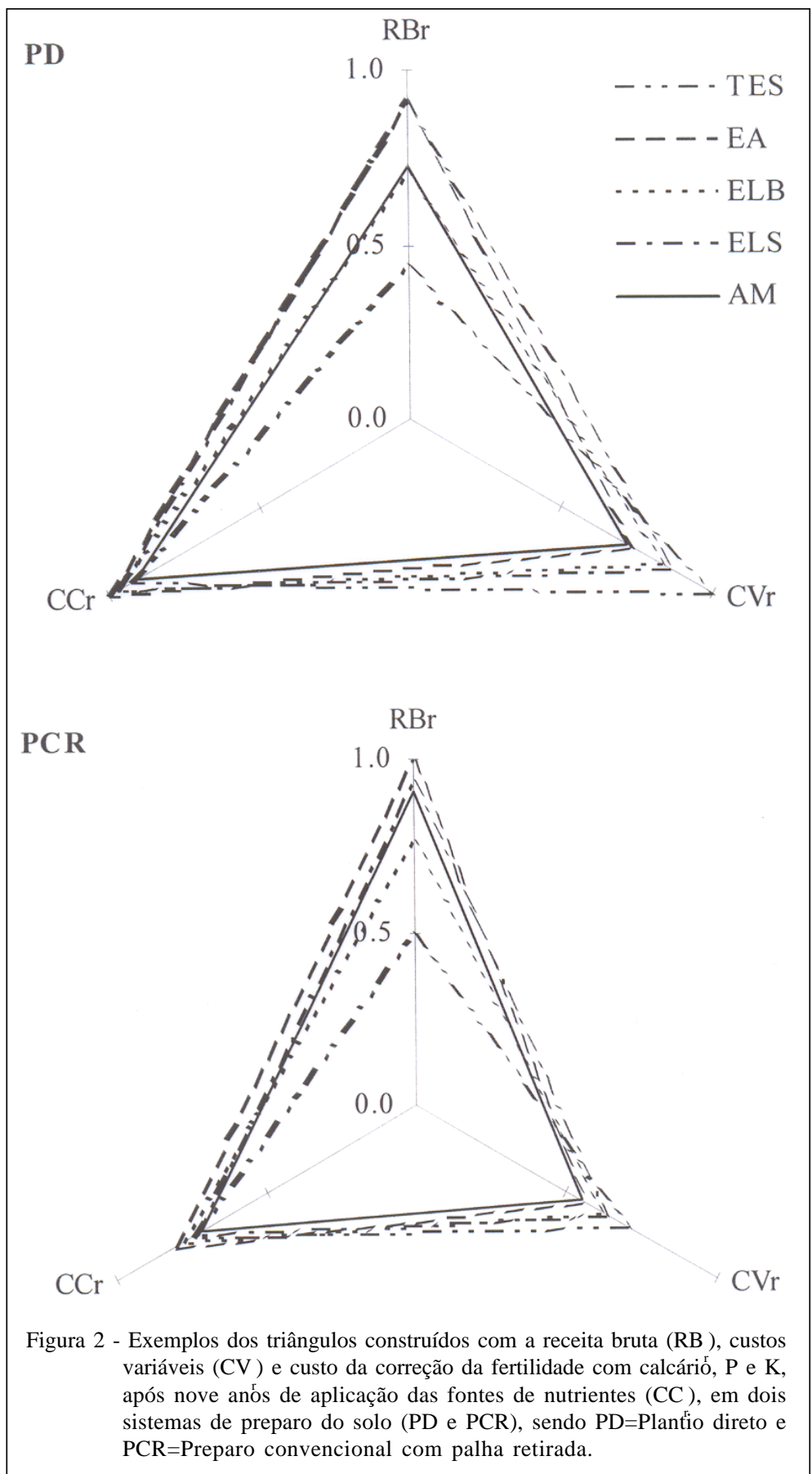

se deve ao menor custo variável de produção, pois não é realizado o preparo do solo, além da maior produtividade obtida no PD. No sistema PCO e suas variações (PCQ e PCR), as áreas dos triângulos das fontes de nutrientes não se diferenciaram, mesmo apresentando valorações diferenciadas entre os atributos. Dessa forma, a menor RB obtida no PCR, considerando a menor produção de grãos, foi compensada pela receita obtida com a venda da palha (feno), já que houve pequena diferença nos demais atributos que compõem a avaliação econômica. Também no PD houve o melhor desempenho econômico do ELB, enquanto que o sistema de preparo não influenciou o AM, pois apresentou áreas dos triângulos semelhantes em todos os casos.

$\mathrm{Na}$ comparação das fontes de nutrientes, considerando todos os sistemas de preparo do solo, observa-se que, com exceção da testemunha, as menores áreas foram obtidas com o ELB e o AM, mostrando que o ELB foi a fonte orgânica de menor desempenho econômico, tanto que o EA se diferenciou do ELB nos cinco sistemas de preparo do solo e o ELB foi diferente do ELS em quatro dos cinco sistemas, exceto para o PCR. Apesar de o ELB não apresentar custo de aquisição, a produtividade de grãos que compõe a $\mathrm{RB}_{\mathrm{r}}$ é mais baixa em relação às demais fontes, fazendo com que o aspecto econômico do ELB não seja satisfatório na dose aplicada, embora poderia ser melhorado em associação

permite afirmar se há diferenças estatísticas, a discussão dos resultados foi efetuada com base na tabela 3 , que apresentada as áreas e os atributos econômicos, com seus respectivos intervalos de confiança.

Com relação aos sistemas de preparo do solo, destacou-se o PD e foi onde houve o melhor desempenho econômico do uso do ELS e EA, cujas áreas dos triângulos foram diferentes das áreas nos demais sistemas de preparo (Tabela 3). Este resultado com uma fonte mineral. Por outro lado, a AM e o EA apresentam custo de aquisição, o que faz com que tenham as menores valorações no atributo $\mathrm{CV}_{\mathrm{r}}$. Isso ocorreu mesmo com o EA apresentando um custo de aquisição de $45 \%$ em relação ao AM. Este aspecto é reforçado pelos resultados de um estudo comparativo entre EA e AM em milho e soja, em que a adubação com EA foi de 18 a 32\% mais barata que a AM (KONZEN, 2003).

Ciência Rural, v.38, n.6, set, 2008. 
Tabela 3 - Média, limite superior e inferior da área do aspecto econômico e dos atributos valorados receita bruta, custo da correção da fertilidade com calcário, P e K, custos variáveis e área para análise dos três atributos conjuntamente quanto as fontes de nutrientes e sistemas de preparos de solo.

\begin{tabular}{|c|c|c|c|c|c|c|c|c|c|c|c|c|c|}
\hline \multirow{2}{*}{ Prep. ${ }^{1}$} & \multirow{2}{*}{ Fonte $^{2}$} & \multicolumn{3}{|c|}{ Receita bruta $\mathrm{RB}_{\mathrm{r}}$} & \multicolumn{3}{|c|}{ Custo da correção - $\mathrm{CC}_{\mathrm{r}}$} & \multicolumn{3}{|c|}{ Custos variáveis $\mathrm{CV}_{\mathrm{r}}$} & \multicolumn{3}{|c|}{ Área } \\
\hline & & Med & $\operatorname{Inf}$ & Sup & Med & Inf & Sup & Med & Inf & Sup & Med & Inf & Sup \\
\hline \multirow{5}{*}{ PD } & TES & 0,43 & 0,35 & 0,50 & 0,93 & 0,90 & 0,96 & 1,00 & 1,00 & 1,00 & 0,76 & 0,70 & 0,83 \\
\hline & EA & 0,89 & 0,83 & 0,96 & 1,00 & 1,00 & 1,00 & 0,74 & 0,73 & 0,75 & 0,99 & 0,95 & 1,04 \\
\hline & ELB & 0,70 & 0,64 & 0,76 & 0,97 & 0,97 & 0,97 & 0,84 & 0,83 & 0,85 & 0,89 & 0,85 & 0,94 \\
\hline & ELS & 0,90 & 0,85 & 0,95 & 0,97 & 0,93 & 1,00 & 0,87 & 0,86 & 0,88 & 1,08 & 1,03 & 1,13 \\
\hline & $\mathrm{AM}$ & 0,72 & 0,64 & 0,81 & 0,91 & 0,88 & 0,93 & 0,72 & 0,71 & 0,73 & 0,79 & 0,73 & 0,85 \\
\hline \multirow{5}{*}{ PRE } & TES & 0,48 & 0,45 & 0,51 & 0,78 & 0,74 & 0,82 & 0,94 & 0,93 & 0,95 & 0,67 & 0,64 & 0,71 \\
\hline & EA & 0,92 & 0,86 & 1,00 & 0,87 & 0,86 & 0,87 & 0,71 & 0,70 & 0,72 & 0,89 & 0,85 & 0,94 \\
\hline & ELB & 0,68 & 0,62 & 0,73 & 0,80 & 0,79 & 0,82 & 0,80 & 0,79 & 0,81 & 0,75 & 0,71 & 0,79 \\
\hline & ELS & 0,91 & 0,85 & 0,97 & 0,85 & 0,80 & 0,90 & 0,82 & 0,81 & 0,83 & 0,96 & 0,90 & 1,02 \\
\hline & $\mathrm{AM}$ & 0,82 & 0,72 & 0,92 & 0,79 & 0,76 & 0,81 & 0,70 & 0,68 & 0,73 & 0,77 & 0,70 & 0,84 \\
\hline \multirow{5}{*}{ PCO } & TES & 0,43 & 0,40 & 0,46 & 0,75 & 0,74 & 0,76 & 0,85 & 0,84 & 0,86 & 0,57 & 0,55 & 0,59 \\
\hline & EA & 0,77 & 0,73 & 0,82 & 0,84 & 0,84 & 0,84 & 0,66 & 0,65 & 0,67 & 0,74 & 0,71 & 0,77 \\
\hline & ELB & 0,62 & 0,56 & 0,69 & 0,79 & 0,79 & 0,80 & 0,73 & 0,72 & 0,74 & 0,66 & 0,62 & 0,71 \\
\hline & ELS & 0,85 & 0,77 & 0,94 & 0,81 & 0,80 & 0,83 & 0,75 & 0,74 & 0,76 & 0,84 & 0,79 & 0,91 \\
\hline & $\mathrm{AM}$ & 0,81 & 0,75 & 0,87 & 0,77 & 0,76 & 0,77 & 0,63 & 0,62 & 0,64 & 0,70 & 0,66 & 0,73 \\
\hline \multirow{5}{*}{ PCQ } & TES & 0,44 & 0,36 & 0,52 & 0,76 & 0,74 & 0,78 & 0,85 & 0,83 & 0,86 & 0,58 & 0,53 & 0,65 \\
\hline & EA & 0,86 & 0,81 & 0,93 & 0,80 & 0,79 & 0,82 & 0,66 & 0,65 & 0,66 & 0,77 & 0,73 & 0,81 \\
\hline & ELB & 0,60 & 0,54 & 0,66 & 0,77 & 0,76 & 0,78 & 0,73 & 0,72 & 0,74 & 0,63 & 0,59 & 0,68 \\
\hline & ELS & 0,85 & 0,72 & 0,99 & 0,77 & 0,72 & 0,81 & 0,75 & 0,74 & 0,76 & 0,81 & 0,71 & 0,90 \\
\hline & $\mathrm{AM}$ & 0,87 & 0,82 & 0,93 & 0,77 & 0,74 & 0,80 & 0,63 & 0,62 & 0,64 & 0,74 & 0,70 & 0,78 \\
\hline \multirow{5}{*}{ PCR } & TES & 0,48 & 0,40 & 0,57 & 0,74 & 0,71 & 0,78 & 0,71 & 0,70 & 0,72 & 0,53 & 0,48 & 0,59 \\
\hline & EA & 0,99 & 0,95 & 1,00 & 0,81 & 0,79 & 0,83 & 0,57 & 0,56 & 0,57 & 0,79 & 0,76 & 0,81 \\
\hline & ELB & 0,75 & 0,66 & 0,84 & 0,78 & 0,75 & 0,81 & 0,62 & 0,62 & 0,63 & 0,67 & 0,61 & 0,73 \\
\hline & ELS & 0,92 & 0,82 & 1,00 & 0,74 & 0,70 & 0,77 & 0,64 & 0,63 & 0,65 & 0,75 & 0,69 & 0,81 \\
\hline & $\mathrm{AM}$ & 0,90 & 0,78 & 1,00 & 0,72 & 0,71 & 0,73 & 0,55 & 0,54 & 0,56 & 0,66 & 0,60 & 0,72 \\
\hline
\end{tabular}

${ }^{1} \mathrm{PD}=$ Plantio direto; $\mathrm{PRE}=$ Preparo reduzido; $\mathrm{PCO}=$ Preparo convencional; $\mathrm{PCQ}=$ Preparo convencional com palha queimada; PCR=Preparo convencional com palha retirada.

${ }^{2} \mathrm{TES}=$ Testemunha (sem aplicação de nutrientes); EA=Dejeto de aves; ELB=Dejeto líquido de bovinos; ELS= Dejeto líquido de suínos; $\mathrm{AM}=$ Adubo mineral.

Os resultados mostraram que o EA e ELS foram as fontes de nutrientes com melhor desempenho econômico porque foram aquelas que apresentaram as maiores áreas. Na comparação dessas fontes, o desempenho foi semelhante porque somente houve diferenciação no PCO, no qual o ELS foi superior ao EA (Tabela 3). Isso reforça a conveniência no uso das doses de EA e ELS utilizadas por SCHERER \& BARTZ (1984) e SCHERER (1998) em condições de solos e culturas semelhantes àquelas utilizadas neste trabalho. Os resultados confirmam observações de KONZEN (2003), que considera que os benefícios econômicos da utilização de dejeto de suínos e de aves na produção de grãos superam os seus custos, sendo um exemplo o trabalho de CHASE et al. (1991), que utilizaram dejetos de suínos no milho por cinco anos e consideraram que o ELS pode substituir o fertilizante comercial com vantagem econômica. Entretanto, SEGANFREDO (2004) ressalta que o uso dos dejetos de animais como fertilizante pode se tornar antieconômico porque os custos de armazenagem e transporte podem ultrapassar o seu valor fertilizante. Isso é particularmente importante para o ELS, pois SCHMITT (1995) mostrou que a distância de transporte foi o principal fator que afetou o custo do metro cúbico de ELS distribuído na lavoura, determinando uma distância viável de transporte muito pequena, de 39 a 1.400m. Entretanto, os dejetos líquidos de suínos podem ser transportados para maiores distâncias na região do Meio Oeste de Santa Catarina, pois SCHERER 
(2005) determinou uma distância máxima de 30km, podendo chegar a $84 \mathrm{~km}$ se o teor de matéria seca do dejeto de suínos passar de 3 para 6\%. Entretanto, CERETTA et al. (2005a) ressaltam que, na tomada de decisão sobre doses de dejeto líquido de suínos, além de o aspecto econômico, deve-se levar em conta aspectos operacionais e ambientais. Além disso, a eficiência no uso dos dejetos líquidos de suínos na produção de grãos ou matéria seca de plantas também determinará variações no seu custo (DURIGON et al., 2002; CERETTA et al., 2005b). Estes são alguns dos aspectos que justificam o fato de o EA ser, normalmente, o mais econômico entre os dejetos, sendo isso devido ao seu alto $\mathrm{pH}$, alto $\mathrm{N}$ inorgânico e baixa relação $\mathrm{C} / \mathrm{N}$ (ARAJI et al., 2001).

Deve-se considerar que, em muitos casos, o uso associado de fontes orgânicas e minerais pode ser vantajoso economicamente e significa o uso mais racional dos nutrientes dos dejetos orgânicos, devido as suas concentrações não-balanceadas em relação às necessidades das plantas. Um exemplo disso foi a maior eficiência mostrada na sucessão centeio/milho, com o uso de EA, a qual tendo baixa taxa de liberação de N, se comparada ao fertilizante mineral, não apenas diminuiu os custos da fertilização nitrogenada no milho, mas também os riscos de lixiviação do nitrato para o lençol freático (NYAKATAWA et al., 2001).

\section{CONCLUSÕES}

O desempenho econômico das fontes orgânicas de nutrientes é dependente do sistema de preparo do solo, sendo que as fontes apresentaram melhor desempenho no sistema plantio direto. O dejeto de aves e o dejeto líquido de suínos são as fontes com melhor desempenho econômico. O dejeto líquido de suínos e o dejeto líquido de bovinos são as fontes com menor variabilidade nos atributos econômicos avaliados, não havendo um atributo que se destaque dos demais. O custo da correção da fertilidade do solo, após nove anos de aplicação das fontes, tem importante participação na avaliação econômica das fontes de nutrientes a longo prazo, porque os efeitos residuais são diferenciados.

\section{AGRADECIMENTOS}

Ao Programa de Pós-graduação em Ciência do Solo da Universidade Federal de Santa Maria e à Empresa de Pesquisa Agropecuária e Extensão Rural de Santa Catarina (EPAGRI), por oportunizar o Curso de Doutorado de Carla Maria Pandolfo, e ao Conselho Nacional de Desenvolvimento Científico e Tecnológico (CNPq), pelo auxílio financeiro e pela bolsa de produtividade em pesquisa para Carlos Alberto Ceretta.

\section{REFERÊNCIAS}

ALTMANN, R.; OLTRAMARI, A.C. A agricultura orgânica na região da grande Florianópolis - Indicadores de desenvolvimento. Agosto 2004. Capturado em 10/01/2005. Online. Disponível na internet: www.icepa.com.br/Publicações/ Agricultura_organica.pdf.

ARAJI, A.A. et al. Efficient use of animal manure on croplandeconomic analysis. Bioresource Technology, v.79, p.179191, 2001.

CERETTA, C.A. et al. Produtividade de grãos de milho, produção de matéria seca e acúmulo de nitrogênio, fósforo e potássio na rotação aveia preta/milho/nabo forrageiro com aplicação de dejeto líquido de suínos. Ciência Rural, v.35, n.6, p.1287-1295, 2005a.

CERETTA, C.A. et al. Dejeto líquido de suínos: I - perdas de nitrogênio e fósforo na solução escoada na superfície do solo, sob plantio direto. Ciência Rural, Santa Maria, v.35, n.6, p.1296-1304, 2005b.

CHASE, C. et al. Economic impact of varying swine manure application rates on continuous corn. Journal of Soil and Water Conservation, v.46, p.460-465, 1991.

COMISSÃO DE QUÍMICA E FERTILIDADE DO SOLO-RS/ SC. Recomendações de adubação e de calagem para os estados do Rio Grande do Sul e de Santa Catarina. 3.ed. Passo Fundo: SBCS-Núcleo Regional Sul, EMBRAPA/CNPT, 2004. 400p.

DURIGON, R. et al. Produção de forragem em pastagem natural com o uso de dejeto líquido de suínos. Revista Brasileira de Ciência do Solo, v.26, p.983-992, 2002.

ICEPA/SC - INSTITUTO DE PLANEJAMENTO E ECONOMIA AGRÍCOLA DE SANTA CATARINA. Florianópolis, 2003. Capturado em 13/10/2003. Online. Disponível na internet: http://www.icepa.com.br.

KONZEN, A.E. Aproveitamento de dejetos líquidos de suínos para fertirrigação e fertilização em grandes culturas. Sete Lagoas:CNPSA, 2003. 11p. (Circular técnica, 32).

NYAKATAWA, E.Z. et al. Residual effect of poultry litter applied to cotton in conservation tillage systems on succeeding rye and corn. Field Crops Research, v.71, p.159-171, 2001.

PANDOLFO, C.M. Aspectos técnico, econômico e ambiental do uso de fontes orgânicas de nutrientes, associadas a sistemas de preparo do solo. 2005. 161f. Tese (Doutorado em Ciência do Solo) - Programa de Pósgraduação em Ciência do Solo, Universidade Federal de Santa Maria.

RASSINI, J.B. et al. Cultivo de alfafa: sistema de produção, 1. Janeiro 2003. Capturado em 29/03/2004. Online. Disponível na internet: http://sistemasdeprodução. cnptia.embrapa.br/ FontesHTML/Alfafa/Sistema ProduçãoAlfafa. 
SCHERER, E.E. Critérios para transporte e utilização dos dejetos suínos na agricultura. Agropecuária Catarinense, v.18, n.1, p.62-67, 2005.

SCHERER, E.E. Utilização de dejeto de suínos como fonte de nitrogênio: bases para adubação dos sistemas milho/ feijão e feijão/milho, em cultivos de sucessão. Florianópolis: Epagri, 1998. 49p. (Boletim Técnico, 99).

SCHERER, E.E.; BARTZ, H.R. Adubação do feijoeiro com esterco de aves, nitrogênio, fósforo e potássio. 2.ed. Florianópolis: EMPASC, 1984. 15p. (Boletim Técnico, 10).
SCHMITT, D.R. Avaliação técnica e econômica da distribuição de dejeto líquido de suínos. 1995. 151f. Dissertação (Mestrado em Engenharia Agrícola) - Universidade Federal de Santa Maria.

SEGANFREDO, M.A. Dejetos animais, a dupla face: benefício e prejuízo. Suinocultura Industrial, v.26, n.183, p.14-16, 2004. (Guia Gessulli, 9).

TEDESCO, M.J. et al. Análise de solo, plantas e outros materiais. Porto Alegre: Departamento de Solos, UFRGS, 1995. 174p. 